
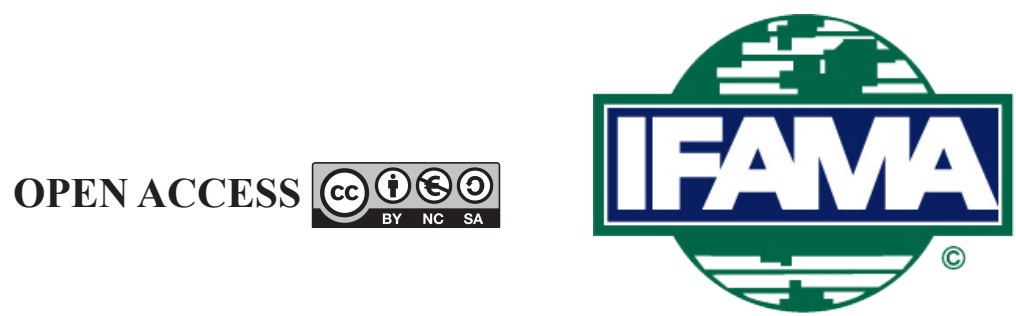

International Food and Agribusiness Management Review

Volume 23, Issue 1, 2020; DOI: 10.22434/IFAMR2019.0049

Received: 1 May 2019 / Accepted: 9 August 2019

\title{
Adoption of e-commerce by the agri-food sector in China: the case of Minyu e-commerce company
}

\section{CASE STUDY}

\author{
Xiaoshan Yang a ${ }^{\mathrm{a}}$ Xiaowei Chen ${ }^{\oplus b, c}$, Yan Jiang ${ }^{\mathrm{d}}$ and Fu Jia ${ }^{\mathrm{e}}$ \\ ${ }^{a}$ PhD, Newhuadu Business School, Minjiang University, No. 200, Xiyuangong \\ Road, Shangjie Town, Minhou County, Fuzhou, China P.R. \\ ${ }^{b}$ Post-Doctoral Research Fellow, School of Public Affairs, Zhejiang University, \\ 866 Yuhangtang Road, Hangzhou, 310058, China P.R.
}

${ }^{c}$ Associate Professor, Zhejiang Gongshang University, No.18 Xuezheng St., Hangzhou 310018, China P.R.

${ }^{d}$ Associate Lecturer in Operations Management, Middlesex University, Business School, Management Leadership \& Organizations, The Burroughs, Hendon, London NW4 4BT, United Kingdom

${ }^{e}$ Professor of Supply Chain Management, The York Management School, University of York, Heslington, York YO10 5DD, United Kingdom

\begin{abstract}
In recent years, increasing numbers of smallholders in developing countries such as China have begun to sell agricultural products directly to consumers via online shops using a third-party trade platform. It is increasingly clear that e-commerce has become a new and effective way to help smallholders gain access to the market. The investigation of agricultural e-commerce practices has a significant role in helping to understand the development of the agri-food sector in China. This teaching case provides an example of adopting e-commerce in the interaction and trading activities between participants in the food sector through a typical agricultural products e-commerce company in China, Minyu E-commerce. Particularly, the case analyzes the business model evolution through the ecosystem life cycle at the company. This case can be used to teach graduate/postgraduate students in agricultural business, MBA and executive programmes about the agri-food e-commerce business model.
\end{abstract}

Keywords: agricultural, food sector, e-commerce, China, business model, teaching case JEL code: Q13

\footnotetext{
${ }^{\circledR}$ Corresponding author: florachenxiaowei@zju.edu.cn
} 


\section{Introduction}

One day, Mr Dehong Huang, President of Minyu E-commerce, was sitting in his spacious office located within the Huaqiao University E-commerce Industrial Park in Qiaozhou City, Fujian Province, pondering the future of Minyu. His thoughts went back to the exciting and unforgettable moments he experienced 3 years earlier. Here, we begin our story.

In 2015, 10 counties $^{1}$ in Fujian Province in China were designated as demonstration counties for e-commerce business, one example of which was Jianning County in Sanming City. To aid the government, which is unable to complete many jobs independently, a collaboration with e-commerce companies is required. Minyu E-commerce Company (Minyu, hereafter) is an agricultural e-commerce service provider that was founded and then invited by the Jianning County government to help develop the local e-commerce business environment.

On August $7^{\text {th }}, 2015$, at the beginning of the collaboration between Minyu and Jianning County government, Fujian Province was hit by Super Typhoon Soudelor. Jianning County is a place known for river rafting expeditions, natural water sources and pollution-free air. The local villagers primarily plant lotus seeds, which are of higher quality levels. Due to the impact of Super Typhoon Soudelor, the lotus-planting farmers suffered heavy losses. The majority of the broken lotuses were mature, with full lotus seeds, and their weight led them to be easily destroyed in the swaying winds. The lotus farmers, therefore, urgently needed to sell their lotus seeds but were receiving one-third of the normal price.

On August $8^{\text {th }}$, a team from Jianning Princess, a local e-tailer with an e-shop on the Minyu platform, visited the county to learn about the damage suffered by the local farmers. By 22:30, the team had calculated that there were 13,000 broken lotuses that had to be sold immediately. Minyu worked overnight to develop an emergency plan for selling the lotus seeds and established a mutual aid group to implement the plan. The plan was effective, and 2,360 lotuses were sold in 30 minutes. Under the joint collaboration of Minyu, the Jianning County Bureau of Commerce, the Jianning Princess team, local farmers, and the Jianning Shuntong Logistics Company, more than 600 cases with a total of 10,320 lotuses were sold by 22:34 on August $9^{\text {th }}$.

This lotus-protection activity helped the farmers to sell more than 13,000 lotuses within 30 hours. Since WeChat ${ }^{2}$ is the most widespread social networking service platform and contains the largest number of users in China, this group adopted WeChat as the platform for selling the lotuses, and some disadvantages emerged during the selling process, i.e. missed and incorrect orders. To solve these problems, Minyu established an e-commerce programme in WeChat - the Huobucuo platform. With this platform, Minyu developed a unique business model and gradually formed its own business ecosystem of agricultural product e-commerce.

Sitting in his office, Mr Huang's thoughts returned to the routine of the day, and he was still puzzled by the direction for Minyu's development. His eyes were red, which was the result of many sleepless nights, a common phenomenon for e-commerce entrepreneurs. One managerial issue was always at the forefront of his mind, which is as follows: what business model can Minyu employ be help the company stay one step ahead of its competitors? There are many specific questions related to this issue, such as the following: as an emerging agricultural product e-commerce company, how should Minyu utilize the established online platform to sell a variety of agricultural products? How could Minyu collaborate with multiple stakeholders to continuously develop its agricultural product e-commerce business? During this process, how would Minyu's agricultural product e-commerce development influence the regional agriculture and rural economy?

\footnotetext{
${ }^{1}$ Counties, formally county-level divisions, are found in the third level of the administrative hierarchy in Provinces and Autonomous regions, and the second level in municipalities and Hainan, a level that is known as the 'county level' and also contains autonomous counties, county-level cities, banners, autonomous banners, and City districts. There are 1,355 counties in Mainland China out of a total of 2,851 county-level divisions. 2 WeChat is a Chinese multi-purpose messaging, social media and mobile payment app developed by Tencent. It was first released in 2011 and became one of the largest standalone mobile apps by 2018, with over 1 billion monthly active users. WeChat has been described as China's 'app for everything' and a 'super app' because of its wide range of functions.
} 
To answer these questions, this case first provides an overview of agricultural e-commerce development in China. Then, it gives the background of Minyu and the challenges Minyu has encountered, followed by the solutions to these problems - the evolution of its business model. Finally, the business ecosystem of agricultural e-commerce is extracted from the evolution of Minyu's business model to deepen the understanding of this teaching case. Supplementary Material S1 contains the list of interviews.

\section{China's agricultural e-commerce overview}

The number of Chinese Internet users has grown rapidly in the past decade, from 298 million in 2008 to 829 million in 2018, including 610 million online shoppers (CNNIC, 2018). According to a $2015 \mathrm{McKinsey}$ report, consumers in China spend an average of 78 minutes per day on social media, and nearly $50 \%$ of Chinese customers make purchasing decisions based on recommendations from relatives and friends (Liu and Rong, 2015).

In light of this situation, e-commerce has become a new driving force for China's economic growth. China's total e-commerce transactions reached 28.9 trillion yuan in 2016 (excluding Hong Kong, Macao, and Taiwan), an increase of $38.9 \%$ over the 20.8 trillion reported in 2015 (UNIDO, 2017). According to calculations by the UNIDO report, the average annual growth rate for China's e-commerce transactions over the past five years was $38.2 \%$ (Figure 1). The single-day trading volume during the 11 November 2016 shopping festival was more than 120.7 billion yuan, and a record was set of 50 billion yuan in trading value in two and a half hours. With its high growth trend, e-commerce has become a new bright spot in China's economy. Chinese e-commerce is predicted to reach 10,345.9 billion yuan in 2020, including online business-to-business (B2B) transactions, which will be greater than that in other developed countries, such as the US, Japan, Britain, and Germany (China Internet Watch, 2013).

Against this background, other changes have occurred in the e-commerce business in recent years. First, agricultural e-commerce has become an industry trend. The Ministry of Commerce and the Ministry of Finance jointly produced a policy to promote the development of rural e-commerce in China. One of its key points was the construction of a multi-level logistics system in rural areas, including the establishment

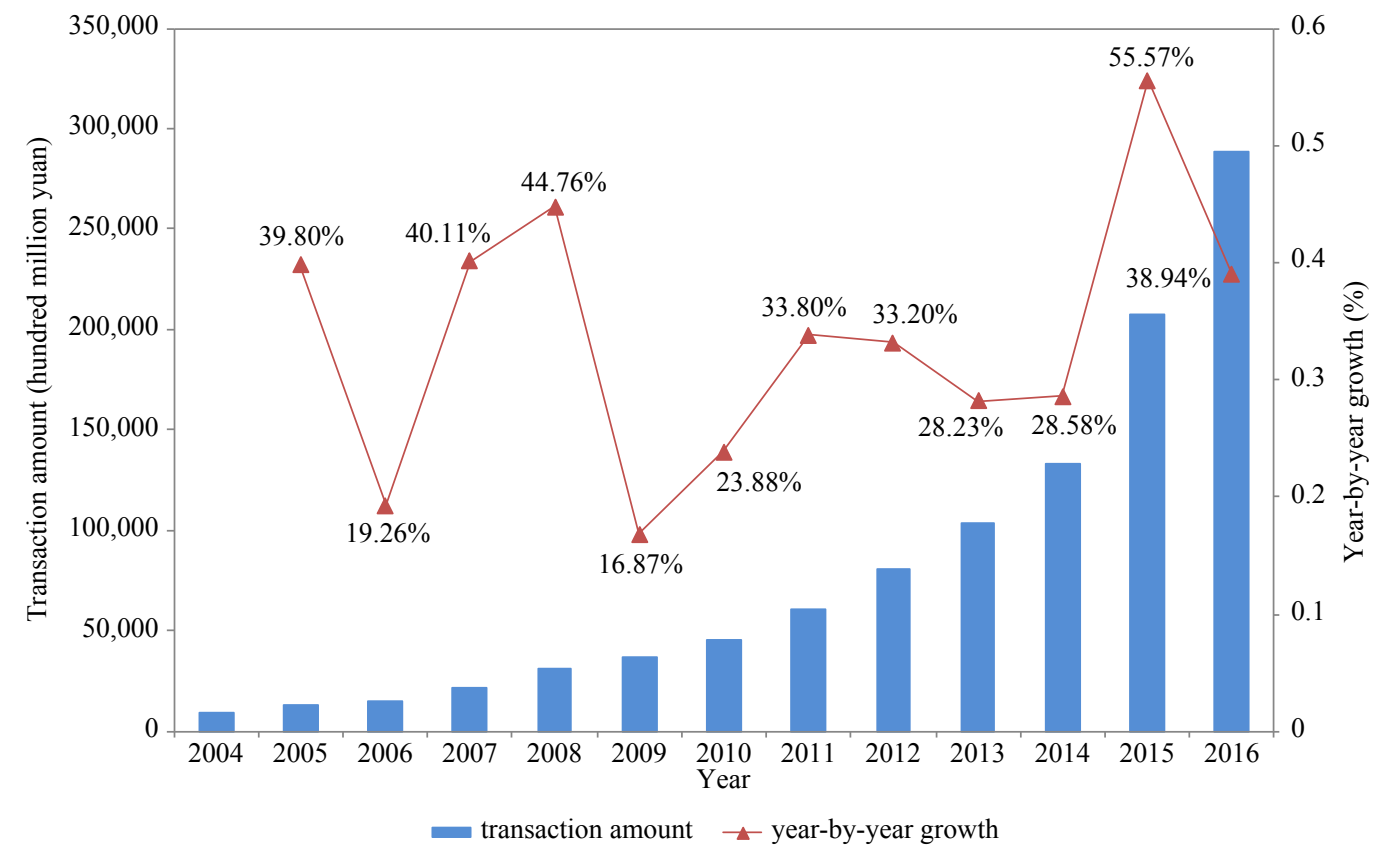

Figure 1. China's total e-commerce transactions (2004-2016) (UNIDO, 2017). 
of county and village level e-commerce centres (Ali Research, 2016). There are six reasons for the focus on developing rural online shopping are as follows: increasing the income of villagers, lagging offline business systems, growing usage of the Internet in these less developed areas, a push delivered through policy, support from e-commerce giants (e.g. Alibaba) and family consumption (Ali Research, 2015a).

Furthermore, agricultural e-commerce has also been developing rapidly in China over the past four years. In 2013 , the growth rate in the amount of online consumer spending in county regions was $13.6 \%$ higher than it was in cities (AliResearch, 2015b). New industries in counties offering services such as delivery, storage, and e-commerce training also grew because of the new economic phenomenon. The most inspiring news is that agricultural e-commerce helped 9.62 million people find jobs (China Association for Employment Promotion, 2013). Agricultural e-commerce has created significant opportunities for regional economic growth (Zeng et al., 2017).

Since 2014, the Chinese Ministry of Commerce, together with the Ministry of Finance and the State Council Poverty Alleviation Office, supported 756 counties in developing their e-commerce business by assigning state funds, representing 56 counties in 2014, 200 counties in 2015, 240 counties in 2016, and 260 counties in 2017 , for a total of 756 counties after four years. Through supporting policies, the government aims to promote e-commerce development and increase farmers' incomes in rural areas, especially in the national priority poverty alleviation and development counties and the regions with concentrated poverty-stricken counties. These example counties can play an exemplary role in developing e-commerce in rural areas in China.

The central government encourages various supporting mechanisms to be adopted by counties, such as equity investment, public-private partnerships, discount loans, etc. In this way, government funds facilitate the engagement of social investment in developing agricultural e-commerce businesses. Agricultural e-commerce development mainly focuses on the following aspects: the uplink of rural products, the construction of public service centres, and training in agricultural e-commerce, making full use of existing industrial parks, idle factories, and the commercialization of e-commerce platforms in the county area to maximize the effectiveness of social resources. Through central fiscal funds, social investment in rural e-commerce work is encouraged, and the following goals are emphasized: focus on the ascendance of rural products, support the construction and transformation of agricultural e-commerce public service centres and rural e-commerce service sites, support e-commerce training in rural areas, and make full use of existing industrial parks, idle factories, and commercialized e-commerce business platforms in the county area to maximize the use of social resources (People's Republic of China Ministry of Commerce, 2017).

Fujian is one of the first provinces to adopt e-commerce in China, and its e-commerce development index was ranked seventh in China in 2015 (National Engineering Laboratory for E-commerce Technology, 2016). The e-commerce transaction volume has grown $40 \%$ over the past three years and reached 711.6 billion yuan in 2015 (Ebrun, 2016). The agricultural e-commerce development index of Fujian Province was ranked third in China. Among the e-commerce demonstration counties in China, Fujian Province accounted for 10 out of 56 counties in 2015 and 7 out of 260 counties in 2017, showing outstanding performance.

Quanzhou Minyu E-commerce Co., Ltd. (Minyu) is an emerging e-commerce company that focuses on developing agricultural e-commerce and creating agricultural e-commerce eco-systems. Minyu has undergone rapid development in recent years and its turnover was approximately 8.8 million yuan in 2016 and 12 million yuan in 2017. Its business models have changed a number of times since its establishment. Minyu is a typical case because it is recognized by the national government as one of the exemplary county-level e-commerce companies in China and has developed a unique business model and ecosystem that helps the company gain a competitive advantage in the national market. 


\section{Minyu's company background and challenges encountered}

Minyu was established on June 26, 2015, with its headquarters located in the Huada E-commerce Zone in the Fengze District of Quanzhou City; it is a comprehensive e-commerce service company. When Minyu was established, the chairman of the company, Dehong Huang, stated the following:

'The current target markets of large-scale e-commerce companies are mainly in cities. Due to limits to the economies of scale, there is less involvement of county-level markets. Therefore, the aim of our company is to identify the subdivided markets, i.e. the county-level markets, and to serve as a leading county-level agricultural e-commerce service provider.'

agricultural products, electronic products, software development, computer system integration services, business information consulting, business management consulting, and communication technology services. To build its own system, Minyu closely collaborates with large platforms, including Alibaba, YHD.com, JD.com, and Tencent, exchanging data, sharing logistics, and receiving technical support. Adhering to the business philosophy of 'growth together' and 'win-win', Minyu is establishing a county-level e-commerce market for agricultural products, expanding the group of e-commerce operators, and promoting the threetier (i.e. county, town, and village) e-commerce channels. In particular, the company provides final Internet technology support through its internal system, i.e. Huobucuo.com.

Minyu has built online shopping malls for different counties as an e-commerce service provider company based on the local e-commerce industry park in each county. By 2016, there were 10 online shopping malls under the Huobucuo.com platform, including Zizhong, Dengfeng, Qingshen, Zhaoan, Lijiang, Nanxian, Yunxiao, Huian, Ningdu and Jianning counties, with each representing a single county.

Qianxian Nonghui, the subsidiary online shopping mall of Huobucuo.com, is mainly responsible for selling local agricultural products nationwide. The organizational structure of Minyu is shown in Supplementary Figure S1. Currently, all items sold are high-quality agricultural products from each of the county-level online shopping malls mentioned above. Huobucuo.com aims to build an IT system supporting a number of online shopping malls and mutual benefit sharing systems. Potentially, online shopping malls could enjoy the benefits of resource sharing and product commonality nationwide. The independent online shopping malls and Qianxian Nonghui are parallel platforms and share the same backstage IT support system (Huobucuo. com) run by Minyu. Some agricultural products are sold on both platforms, and these are linked to each other on their web pages. There are recommendations and resource sharing among these platforms. The agricultural products are not only sold on the county-level online shopping malls but are also available on Qianxian Nonghui and other counties' online shopping malls.

After the initial structure of Minyu was established, the company encountered the same challenges as many other e-commerce companies in China. These challenges include the following: (1) the economy of scale and standardization of agricultural products are low; (2) the transaction information of agricultural products is asymmetric; (3) the upstream and downstream portions of the industrial chain are highly dispersed; (4) the infrastructure for e-commercialization of agricultural products is still underdeveloped, and the application level of technology is low; (5) the storage and logistics facilities of both the production origins and the markets cannot meet the needs of the agricultural products' sales; (6) most of the sales are the raw materials of agricultural products, of which the added value is very low, resulting in the little profit and a lack of funds for the e-commerce companies; (7) most e-commerce companies are still in the early stage and do not engage with their various stakeholders effectively; and (8) many e-commerce companies have weak brand awareness and neglect to maintain their customer relationships. In response to these challenges, Minyu has developed unique business models at various stages of its development. 


\section{Business model evolution of Minyu}

Business models can help firms to differentiate themselves from their competitors and, therefore, they can be viewed as an important source of competitive advantage. A general business model structure is provided in Supplementary Material Table S1, which stipulates nine basic building blocks. Currently, the key development of Minyu's e-commerce business can be divided into the following three stages: birth, expansion, and leadership. At each stage, Minyu has formed a distinct and innovative business model that indicates the development objective, the business strategy, and the corresponding practices of its agricultural product e-commerce.

\subsection{Birth (August to December 2015)}

After 2013, as the biggest business platform, Taobao's entry threshold had become increasingly high, with cumbersome and changeable rules. At the same time, merchants were required to participate in Taobao's various activities (such as the 'double eleven'3 promotion), so that the profit margin was seriously reduced to boost online promotions. Qingfu Zhang, a shop owner of Qianxian Nonghui, said the following:

'Taobao is the most difficult platform to manage well for us because of its high entry threshold and high cost of participating in the platform promotion activities and improving the number of visits.'

Therefore, the survival rate for small and medium-sized enterprises in Taobao has been low in recent years, and small online shop owners are forced to seek new sales channels. Given that agricultural products are seasonal, the e-commerce platforms for agricultural products in China took collective action to promote selected seasonal agricultural products. At the birth stage, Minyu grasped opportunities, provided high-quality agricultural products for online customers, and created value for consumers.

The establishment of Qianxian Nonghui was sparked by the opportunity to develop agricultural e-commerce aiming to help the farmers suffering from a typhoon by selling local lotus seeds in Jianning County in August 2015. This activity was promoted by the members of Minyu by using WeChat (the Chinese equivalent of Facebook). Minyu was invited by a small local agricultural e-commerce shop called Jianning Princess to host this promotion activity. At that point, Minyu identified the business opportunity to develop agricultural e-commerce and established Qianxian Nonghui, which was a platform for selling agricultural products. This platform not only unites and manages the WeChat shops/sellers that sell local agricultural products but also provides a distribution channel for some larger companies to broaden their market.

At the same time, Minyu continued to seek cooperation with other e-commerce industrial parks in counties nationwide, building online shopping malls for each area, which helped to broaden the distribution channels for local agricultural products. All county-level online shopping malls used the same management pattern. The Chairman Dehong Huang provided the following observation:

'We must make full use of the resources of the China County E-commerce Alliance to help each other and repatriate the special products from all parts of the country. In addition, he also pointed out: the early opened stores in Taobao that sell agricultural products generally have good earnings. But with the continuously increased entry threshold, more and more stores in Taobao are having difficulty earning in the recent year and are finally exiting from Taobao. Our company aims to unite these people selling high-quality agricultural products on the Huobucuo platform.'

Compared with other e-commerce platforms, such as Taobao and T-mall, the greatest advantage of the Huobucuo.com system in that period was that it gathered agricultural products from around China. These products have different harvesting and selling seasons, so small e-commerce stores could distribute the

\footnotetext{
${ }^{3}$ Double eleven symbolises single men and women; this is a sales promotion activity held by Taobao on the $11^{\text {th }}$ of November every year.
} 
appropriate products for each season according to the market requirements. The Huobucuo.com system identifies the source of goods for online e-commerce stores and works diligently to gradually reduce the distribution costs.

Ting Li, an e-businessman within Jianning Mall, stated that the fruits grown in their county are mainly Huanghua Pears and Kiwis, which are only ready for harvesting in the summer. After entering Jianning Mall, the out-of-season fruit supply issue was solved because they could distribute other winter fruits sold in the online shopping malls of different counties, such as blood oranges (a type of orange that is the colour of blood) in the online shopping mall of Zizhong County. These out-of-season fruits from distant provinces sold at a reasonable price are popular among many Chinese consumers, so this resource-sharing method significantly expanded the reach of agricultural products.

Another advantage of this system is that all online stores are operated by the Huobucuo.com system. In other words, Minyu is responsible for the web page design, product introduction, advertising, promotion and so on. The e-businesses only need to focus on selling products and obtaining new distributors. It is much easier to run an online shop at Qianxian Nonghui than on other platforms.

At the birth stage of the business model formation, the company's customers were online shoppers. Minyu sold goods through distributors, who established an extensive WeChat network of customers and built friendship-like business relationships, with interactions in real life, and distributors advertised products through the 'WeChat Moment' ${ }^{4}$ and attracted friends to buy the products. The after-sale services could only be provided by online customer service personnel through WeChat.

Considering the value orientation, the company could provide a limited range of agricultural products, and the packaging was not attractive, but the products marketed were of reliable quality and met the customers' demand for quality products. Meanwhile, the company's channel was ensuring on-time in-full delivery of goods and attracting consumers through online promotions. The company was not involved directly in co-operating with suppliers and distributors or with other ecosystem partners, such as logistics and design providers.

In terms of the cost structure, General Manager Zhang explained that in the early stage of Minyu's development, investment reached 5 million yuan a year, mainly for travel expenses and staffing costs. Because of product positioning, before the establishment of the ecosystem, the company selected products by visiting suppliers, so three-fifths of the funds were for travel and staff expenses. However, the source of income at this stage was only focused on distribution. In the early days of the company, there were few consumers and profits were thin, so at this stage, spending was far greater than income.

At the birth stage, an agricultural product e-commerce company needs to promote the value of a new product or service and determine the best channel for delivering it. Minyu focused on developing agricultural products and making them suitable for online sales, promoting featured agricultural products for each county. The summary of the business model innovation at this stage is shown in Table 1.

\subsection{Expansion (January-September 2016)}

At this stage, Minyu began to introduce wholesalers and streamline the upstream supply chain. The company searched for qualified wholesalers in counties to provide products with quality assurance (e.g. traceability) and relied on the amenities (e.g. facility and logistics) of the industrial parks. Products could be supplied and shipped directly from the place of production, and industrial parks could also provide storage services. Compared with decentralized suppliers, using the same supplier could reduce costs. When Huanghua pears

\footnotetext{
${ }^{4}$ WeChat Moment provides new social-networking functions for Wechat users. Users can share and obtain access to accepted WeChat friends' information, creating an intimate and private communicating circle within the users' choice of close friends. WeChat Moments mainly focus on sharing pictures with captions, while sharing statuses and sharing websites are also permitted.
} 
Table 1. Minyu's business model at birth stage.

\begin{tabular}{lllll}
\hline Key partners: & Key activities: & Value proposition: & Customer relationships: & Customer segment: \\
\hline $\begin{array}{l}\text { Suppliers; } \\
\text { Distributors }\end{array}$ & Product publicity & $\begin{array}{l}\text { Provision of } \\
\text { traditional } \\
\text { agricultural products }\end{array}$ & WeChat friends & Online shoppers \\
\hline & Key resource: & Channel: & \\
\hline & Social media & Internet sales & \\
\hline Cost structure: & & \multicolumn{2}{c}{ Revenue streams: } \\
\hline Cost of labour; travel allowance & \multicolumn{2}{c}{ Commission } \\
\hline
\end{tabular}

were sold in Jianning between April and August in 2016, Minyu introduced the Xiangtian Grain E-commerce Co., Ltd. (in short, Xiangtian Grain) in Jianning as the sole supplier of the Huanghua pears produced in Jianning County. All the sales of Huanghua pears through the distribution network under the Huobucuo.com system were delivered by Xiangtian Grain, which reduced the cost of delivery. Meanwhile, e-businesses can dis-intermediate by obtaining goods directly from wholesalers without brokers and agents and can thereby substantially reduce the distribution costs. The General Manager, Genlin Li, who is responsible for the promotion of Huanghua pears, stated the following:

'We aim to create a good impression of the e-commerce consumers of Huanghua pears in Jianning County so that consumers can understand Jianning County considering local culture, product quality, and environmental ecology. We developed the product standards for the uplink e-commerce of Huanghua pears, which has enhanced the market bargaining power of Jianning Huanghua pears and created a county-level regional brand for Jianning County. Particularly, we strictly control product standards through a sequence of activities, including: (1) selecting qualified farmers; (2) confirming collaborations; (3) ensuring quality standards; (4) developing the specification of uplink products; (5) testing the size of product packages; (6) standardizing the delivery process.'

Simultaneously, at this stage, the company was trying to build agricultural product online shopping malls and online to offline (O2O) shopping platforms in each county. Physical stores opened virtual ones in the agricultural products online shopping mall, which played the role of an online supermarket. The residents of the county not only bought fresh fruits and vegetables, meat and commodities at the local online shopping mall but also enjoyed other services, e.g. restaurants, hotels, supermarkets, car washes, and taxi companies. Local residents became accustomed to shopping at Jianning Mall. Although there are many mobile applications offering similar services, such as DIANPING.COM (the Chinese equivalent of TripAdvisor) and Di Di taxi (the Chinese equivalent of Uber), these are mainly for urban users and generally cannot be used in rural areas, so local residents often do not use them.

Shanbo Li, the Operation Director of Huobucuo platform, stated the following:

'The Huobucuo platform supports two business projects. One is the Qianxian Nonghui project, which mainly sells high-quality agricultural products from each merchant settled in the platform. The other is the County Mall, which is our priority in the following business development. Each county has large department stores or supermarkets, and they can settle in our platform. The residents of the county, when shopping, do not need to go out of their house, as they can just order on the County Mall on our platform. Through localized delivery, they can receive the products on the same day, which is very convenient for the lives of local residents.' 
In the future, as other applications enter the county market, various malls under the Huobucuo.com platform could be used to attract local residents. Liu Xuying, a resident of Jianning, said that she loves to buy daily necessities on the Jianning Mall not only because there is no difference in quality between the online and offline products but also because the products can be delivered quickly to her home. Developing the county domain $\mathrm{O} 2 \mathrm{O}$ could promote the agricultural product online shopping mall and bring more visitors to the platform.

At this stage, the business of the company's online retailers also included providing advice services for e-tailers, e.g. brand planning, packaging recommendations, and logistics solutions. When the customer completed a purchase transaction at the distributor, the suppliers were responsible for fulfilling the orders and dispatching the shipments. Minyu helped the suppliers to use a logistics company that could meet the transportation requirements based on the characteristics of the product. For example, they advised a supplier of aquatic products to use ShunFeng Courier, which could ensure the freshness of the product.

Value positioning, at the expansion stage, aimed to deliver value to a large number of customers and expand the market. According to the Ninghua County Bureau of Commerce e-commerce and information unit staff, Sun Jie, in this stage, low value-added products, the inconvenience of transportation, and information asymmetry posed difficulties in the development agricultural e-commerce. Minyu enhanced the value of positioning in the expansion phase further by co-operating with suppliers and aiming at solving the problem of low value-added products by providing brand planning, product design, unified packaging, and technical services. When product quality can be guaranteed, customers are more willing to buy goods at a relatively higher price and will return for more products, thereby improving the sales income.

Minyu segmented consumers by differentiating between local and national consumers during the expansion stage, and it invited more e-commerce companies (online shops) to the platform. Minyu provided online shop management services to e-commerce companies on the platform, charging reasonable service fees. In addition to agricultural product suppliers and distributors, Minyu also built relationships with key partners, including packaging design companies, such as Xiamen RuGuo GuangNian Culture Communication Co., Ltd., which was one of the early companies established by Huang Dehong, the chairman of Minyu and is mainly responsible for the packaging design for the suppliers of agricultural products and for the sale of cultural and creative products (e.g. Iven rabbits).

At the same time, to develop the agricultural product e-commerce, Minyu integrated online shops and offline promotions at the local retail shops, created the online agricultural product shopping mall/platform and encouraged local residents to begin shopping regularly on the online platform. First, this behaviour improved the county e-commerce system; second, it brought together potential customers and distributors for agricultural product sales under the Huobucuo.com platform.

In terms of the cost structure, as a result of the company's product positioning, which allowed e-commerce companies to open online shops without any constraints, there was no longer a need for the company to send a team for supplier qualification, so travel was not a major expenditure at this stage. Because certain programmes needed to be professionally designed to provide value-added services for suppliers, the salaries of the technical staff were the main expenditures at this stage. In addition to obtaining commissions from online sales, the income stream also included network service fees. As expenses were reduced and the sources of income increased, the company started making a small profit, which compensated for the losses from the previous stage. Table 2 provides a summary of the nine components of the business model at the expansion stage. 
Table 2. Minyu's business model at the expansion stage.

\begin{tabular}{|c|c|c|c|c|}
\hline Key partners: & Key activities: & Value proposition: & Customer relationships: & Customer segment: \\
\hline \multirow[t]{3}{*}{$\begin{array}{l}\text { - Suppliers; } \\
\text { distributors } \\
\text { - Culture and } \\
\text { creative company }\end{array}$} & $\begin{array}{l}\text {-Product publicity } \\
\text {-Value-added } \\
\text { services }\end{array}$ & $\begin{array}{l}\text { - Traditional } \\
\text { agricultural products } \\
\text { •Brand design }\end{array}$ & $\begin{array}{l}\cdot \text { WeChat friends } \\
\text { - Cooperative partners }\end{array}$ & $\begin{array}{l}\text {-Customer segment: } \\
\text {-Online shoppers } \\
\text { •E-commerce } \\
\text { companies }\end{array}$ \\
\hline & Key resource: & & Channel: & \\
\hline & $\begin{array}{l}\text { - Social media } \\
\text { - Skills }\end{array}$ & & $\begin{array}{l}\text { - Web sales } \\
\text { - Communication }\end{array}$ & \\
\hline Cost structure: & & & Revenue streams: & \\
\hline \multicolumn{2}{|c|}{ Salary of technical staff } & & $\begin{array}{l}\text { - Commission } \\
\text { - Service fee }\end{array}$ & \\
\hline
\end{tabular}

\subsection{Leadership (October 2016 onwards)}

At the leadership stage, Minyu was searching for raw material suppliers, negotiating for the best price with the top suppliers on behalf of the online shops and even providing a supply chain financing service to both online shops and suppliers. For example, the company found the suppliers for a restaurant on the platform and arranged the entire supply process. In this way, Minyu can purchase raw materials from farmers at a low price and then provide a reasonable price to the online restaurant, which will integrate upstream suppliers. Shanbo Li said the following:

'The ultimate goal of our platform is operating the online B2B transactions, integrating the resources in the upstream supply chain. The merchants on the platform have various needs for the raw materials; the platform can aggregate these individual needs and then negotiate with suppliers. For example, the stores purchase eggs at a price of 3.80 yuan in the daily transaction. Through integrating the resources and aggregating the individual needs, the platform can negotiate with suppliers and get a price of 3.30 yuan. Then, the platform sells eggs to the stores at a price of 3.50 yuan and earns the price difference. In this way, the stores on the platform can also purchase eggs at a lower price.'

Another example is mentioned by Genlin Li, as follows:

'When stores sell Jianning Huanghua pears, the packages are centralized and purchased by the platform at a lower price, which helps the stores save the cost of packaging. At the same time, the platform negotiates with the logistics companies and reduces 1.00 yuan for each parcel, which helps the stores save the cost of logistics.

Minyu focused on integrating the upstream supply chain resources and searching for the suppliers of raw agricultural product materials and negotiating with them for a lower price. Then, it started selling the raw materials to e-tailers on the platform at below-market prices to make a profit. The value proposition for online shops was focused on the integration of upstream supply chains.'

Because the expenses remained the same as those during the expansion stage, the company's earnings greatly improved during this stage, and the e-tailers needed to set a development direction to encourage all partners to grow. At this stage, Minyu became the core platform for all nodes of its supply chain and promoted the development of an entire business ecosystem. Table 3 provides a summary of the nine components of the business model at the leadership stage. 
Table 3. Minyu's business model at the leadership stage.

\begin{tabular}{|c|c|c|c|c|}
\hline Key partners: & Key activities: & Value proposition: & Customer relationships: & Customer segment: \\
\hline \multirow[t]{3}{*}{$\begin{array}{l}\text { - Suppliers; } \\
\text { distributors } \\
\text { - Culture and } \\
\text { creative company }\end{array}$} & $\begin{array}{l}\text { - Product publicity } \\
\text { - Value-added } \\
\text { services } \\
\text { - Negotiation }\end{array}$ & $\begin{array}{l}\text { - Traditional } \\
\text { agricultural products } \\
\text { - Brand design } \\
\text { - upstream integration }\end{array}$ & $\begin{array}{l}\text {-WeChat friends } \\
\text { - Cooperative partners } \\
\text { - Upstream suppliers }\end{array}$ & $\begin{array}{l}\text { - Online shoppers } \\
\text { - E-commerce } \\
\text { companies } \\
\text { - Material suppliers }\end{array}$ \\
\hline & Key resource: & & Channel: & \\
\hline & $\begin{array}{l}\text { - Social media } \\
\text { - Skills }\end{array}$ & & $\begin{array}{l}\text {-Web sales } \\
\text { - Communication } \\
\text { - Negotiation }\end{array}$ & \\
\hline Cost structure: & \multicolumn{4}{|c|}{ Revenue streams: commission } \\
\hline \multicolumn{2}{|c|}{ - Salary of technical staff } & \multicolumn{2}{|c|}{$\begin{array}{l}\text { - Commission } \\
\text { - Service fee } \\
\text { - Price difference }\end{array}$} & \\
\hline
\end{tabular}

\subsection{The Minyu's business model innovation pattern}

Minyu has a continuous process of business model innovation, which is characterized by a multi-sided platform pattern. The company connects two or more consumer groups that were previously independent of each other and plays the role of mediator to create value for each group. At the same time, there is a specific product and source of income corresponding to each consumer group. Minyu's customer groups have gradually increased. Online shoppers were the initial customer group, and then e-tailers became another customer group. The former are customers of the latter.

At the same time, Minyu's business ecosystem is also a mutual co-operation and co-evolution system. In the process of development, the different stakeholders can simultaneously make progress by working with the core platform and achieving a win-win situation. The nine fundamental components can be summarized as the following four parts: customer, product innovation, infrastructure management, and financials. Minyu's business models for the three phases of its lifecycle are compared based on the four dimensions in Table 4.

Table 4. Minyu's business model innovation evolution.

\begin{tabular}{|c|c|c|c|}
\hline & Birth & Expansion & Leadership \\
\hline Customers & $\begin{array}{l}\text { One-sided customer, } \\
\text { e.g. online shoppers }\end{array}$ & $\begin{array}{l}\text { Multi-sided platform, } \\
\text { e.g. online shoppers and } \\
\text { e-commerce customers }\end{array}$ & $\begin{array}{l}\text { Multi-sided platform integrating the } \\
\text { supply chain, e.g. online shoppers, } \\
\text { e-commerce customers and suppliers }\end{array}$ \\
\hline Product innovation & Products & Products + services & $\begin{array}{l}\text { Products }+ \text { services }+ \text { upstream } \\
\text { integration }\end{array}$ \\
\hline $\begin{array}{l}\text { Infrastructure } \\
\text { management }\end{array}$ & Social media & $\begin{array}{l}\text { Social media }+ \text { local } \\
\text { e-commerce park }\end{array}$ & $\begin{array}{l}\text { Social media }+ \text { upstream suppliers }+ \\
\text { local e-commerce park }\end{array}$ \\
\hline Financials & Cost $>$ Revenue & Cost $\approx$ Revenue & Cost $<$ Revenue \\
\hline
\end{tabular}




\section{Business ecosystem of Minyu's agricultural ecommerce products}

In the process of the evolution of Minyu's business models, an integrated business ecosystem was gradually established. Figure 2 shows the mapping of the agricultural product e-commerce business ecosystem based on the ecosystem-mapping tool.

\subsection{Core business}

The business ecosystem of Minyu consists of three parts, i.e. the core business, the expanded enterprise, and the whole business ecosystem. The core business of the system is formed by direct suppliers and distributors (Figure 3). The direct suppliers include small e-commerce companies (e.g. Jianning Princess) and wholesalers (e.g. Xiangtian Grain). They are included in the Qianxian Nonghui platform or agricultural product online shopping malls supported by the IT system of Huobucuo.com to sell products. At the same time, Qianxian Nonghui provides business advice to direct suppliers to ensure product quality. There are two channels of distribution. One is the type of distributor under the three-level distribution system. Another is the legion mode of distribution channel, in which distributors send product information to WeChat friends to attract friends to buy, thereby becoming the next level of distributors to expand the sales channels. After customers place the purchase order, the goods will be sent directly from the suppliers to the customers without going through the distributors. The payment for goods is made by the customers to the suppliers through WeChat Pay, an online payment system managed by the company Tencent. The commission and payment are distributed by the Huobucuo.com IT system and are paid to the distributors and direct suppliers, respectively.

\subsection{Extended enterprise}

The extended enterprise is formed by farmers, service providers, offline stores, logistics companies, design companies, and the WeChat social networking platform. There are three ways e-commerce companies (online shops) are supplied with goods, and they are as follows: directly from farmers, from wholesalers (who are

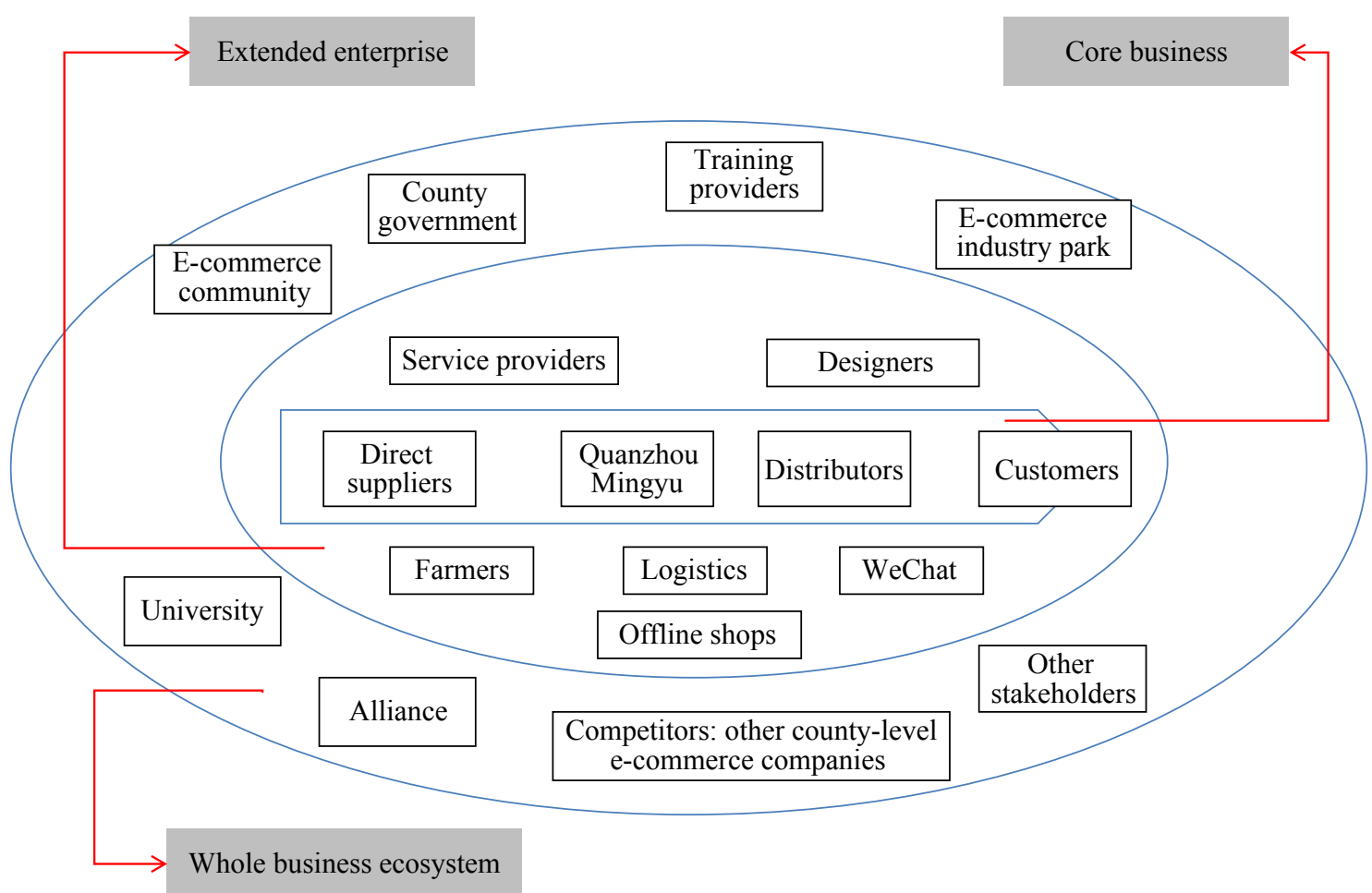

Figure 2. Ecosystem map. 


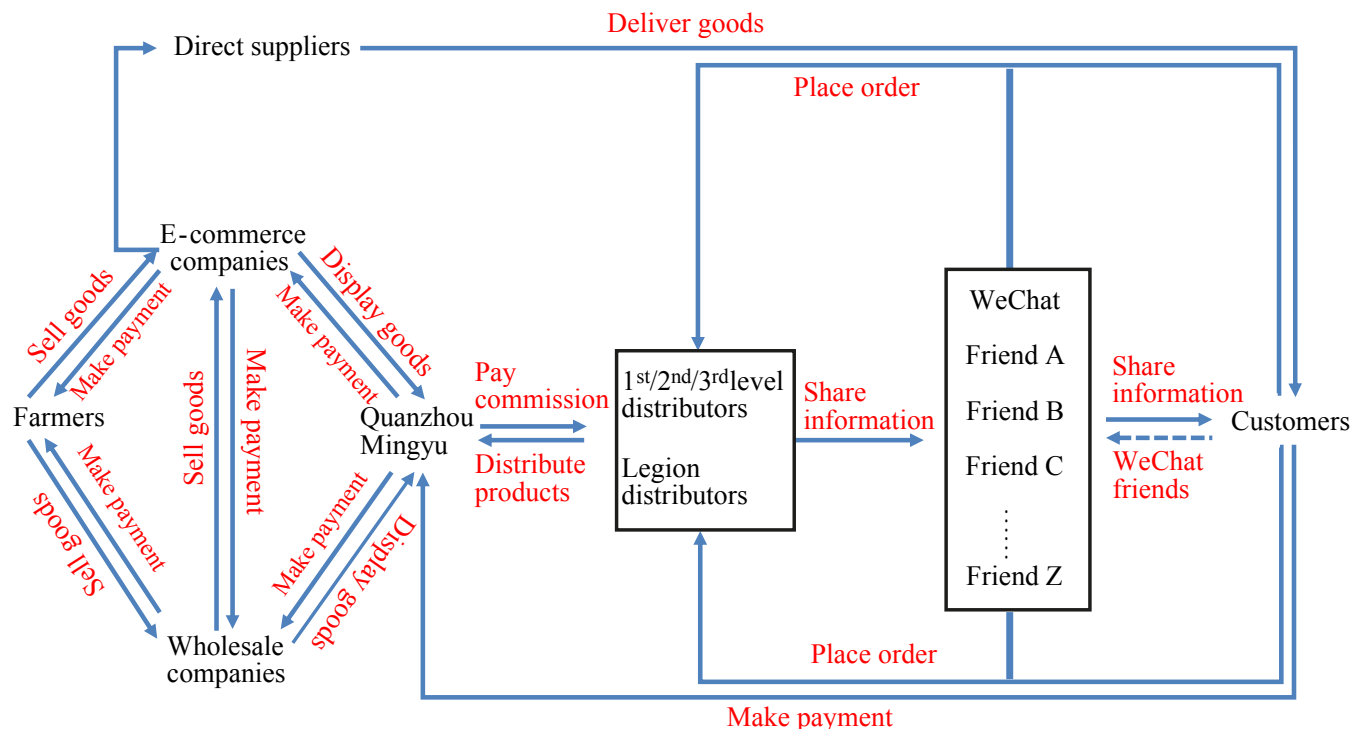

Figure 3. Core business ecosystem.

supplied by farmers) and through their own production of goods (from their own farms). For example, the Jinnuo Barley Professional Co-operative in Ninghua, as a wholesaler, purchases barley from farmers first and then sells it to Jianning Princess and other e-commerce companies on the platform. In the season for selling Huanghua pears, the wholesalers are responsible for product quality control, picking, packaging, transportation and other components of the front-end product supply chain and delivering the products on behalf of the distributors. Although the farmers produce goods, they cannot become direct suppliers selling goods online because they lack online selling knowledge.

Offline stores, such as restaurants and supermarkets, open virtual shops at the agricultural product online shopping malls and become suppliers of complementary products and services to the online shopping platform. City customers purchase the goods online, which are then distributed by the stores. As a social networking platform, WeChat aims to connect consumers and distributors and is an important part of ensuring that the e-tailer's core business is completed and promoting the development of e-tailers. Consumers share product information through WeChat, which expands the consumer groups and turns friends into customers of customers. Logistics companies provide transportation services for the goods, and design companies provide packaging design services for the suppliers.

\section{Looking forward}

As commented by Mr Dehong Huang, the adoption and development of e-commerce is an innovative way of influencing food systems and providing market access to smallholders. Particularly, the regional development of agricultural product e-commerce and its impacts on agriculture, farmers, and the rural economy propose significant agri-food policy implications for the developing countries.

The agricultural product e-commerce business ecosystem created by Minyu has solved the problems commonly seen in traditional online platforms in China through providing a reputation system that collects feedback from buyers/consumers regarding past transactions to address these problems. First, in terms of price, the selling price is relatively lower because products have been supplied directly by suppliers and there is no intermediation cost in the transaction process. Second, in terms of agricultural products, Minyu has successfully improved the traceability of agricultural products. Customers are able to track detailed information of each product to its origin, so product quality problems caused by information asymmetries have been significantly reduced. 
However, there are also disadvantages regarding Minyu's development of its business model and ecosystem, which require additional effort and engagement. First, in its current supply chain, Minyu lacks in-house warehouses as well as a self-built logistics hub, which causes the company to have a weak logistics flow; meanwhile, due to the lack of a traceability system and comprehensive information system, the information flows in the supply chain are also not sufficient. Second, in terms of platform management, Minyu provides a limited number of certification schemes and only applies ex-ante regulation (monitoring/checking before an e-tailer starts operating at the platform), as opposed to ex-post regulation on the platform; this cannot guarantee quality. At the same time, the lack of a specialized department and marketing experience results in weak marketing services. Third, as the e-commerce service provider reached the leadership stage, the innovation orientation of Minyu remained at a low level and many of its internal teams still work independently. All these issues should be taken into consideration by Minyu to gain more competitive advantages and create greater value for its customers.

In the future, with the growing number of merchants entering the platform and the extension of distributor and consumer groups, Minyu will additionally provide a supply chain financing service to both online stores and suppliers. The vice chairman of Minyu, Junxiang Xiao noted that with the increasing platform flow, funds would be deposited on the platform. Internet finance is an important business for the future development of Minyu, and it can provide loans for the merchants on the platform. Minyu has been established to support national agricultural e-commerce development, a role that will eventually end in the future. During this process, customers and resources need to be continuously accumulated and deposited on the platform, as this will help Minyu prevent potential problems in the future.

\section{Supplementary material}

Supplementary material can be found online at https://doi.org/10.22434/IFAMR2019.0049

Figure S1. The business structure of Minyu E-commerce Co., Ltd.

Table S1. Business model canvas.

Table S2. List of interviews.

Teaching Note.

\section{Acknowledgements}

This research was funded by Provincial Natural Science Foundation of Fujian in China (2018Z01812); the Foundation of the Education Department of Fujian Province (JAS14245); Zhejiang Provincial Natural Science Foundation of China under grant number LY19E080006; China Postdoctoral Science Foundation (2018M642391).

\section{References}

Aliresearch. 2015a. Discovery of a new blue ocean. Aliresearch Institute Released Rural Online Shopping Reports. Available at: http://www.aliresearch.com/blog/article/detail/id/20543.html (in Chinese)

Aliresearch. 2015b. Gao Hongbing: discover the county economy from the internet +. Available at: http:// www.aliresearch.com/blog/article/detail/id/20351.html?spm=a2z07.7681614.0.0.Ue3jPt (in Chinese)

Aliresearch. 2016. 2015 e-commerce inventory: electronic commerce has become a new driving force for China's economic growth. Available at: http://www.aliresearch.com/blog/article/detail/id/20777.html

China Association for Employment Promotion. 2013. The focus on the employment in China. China Labour Social Security Press, China P.R.

China Internet Watch. 2013. China e-commerce market to reach 30 trillion Yuan in 2020. Available at: http:// www.ChinaInternetwatch.com/2007/China-e-commerce-market-2020/

China Internet Network Information Center (CNNIC). 2018. Statistical report on internet development in China. Available at: https://cnnic.com.cn/IDR/ReportDownloads/201807/P020180711391069195909.pdf 
Ebrun. 2016. Liang Jianyong: Fujian e-commerce trading amount reached 711.6 billion in 2015. Available at: http://www.ebrun.com/20160328/170506.shtml (in Chinese)

Liu, G. and K. Rong. 2015. The nature of the co-evolutionary process complex product development in the mobile computing industry's business ecosystem. Group \& Organization Management 40(6): 809-842.

National Engineering Laboratory for E-commerce Technologic. 2016. China electronic commerce development index report from 2014 to 2015. Available at: https:/www.nelect.org/ebindex/2016.pdf

Osterwalder, A. and Y. Pigneur. 2010. Business model generation: a handbook for visionaries, game changers, and challengers. John Wiley \& Sons Inc., Hoboken, NJ, USA.

People's Republic of China Ministry of Commerce. 2017. Notice on launching 2017 e-commerce integrated rural demonstration work. Available at: http://www.gov.cn/xinwen/2017-05/19/content_5195244. htm (in Chinese)

United Nations Industrial Development Organization (UNIDO). 2017. National report on e-commerce development in China. UNIDO, Vienna, Austria. Available at: https://www.unido.org/api/opentext/ documents/download/9921295/unido-file-9921295

Zeng, Y., F. Jia, L. Wan and H. Guo. 2017. E-commerce in agri-food sector: a systematic literature review. International Food and Agribusiness Management Review 20(4): 439-460. 
